\title{
Covid-19: Trump cancels all flights from Europe, apart from the UK
}

\author{
Janice Hopkins Tanne
}

New York, USA

President Donald Trump announced on Tuesday night in a national TV broadcast that the US would be closed to all flights from Europe-excluding the UK-for 30 days from midnight on Friday 13 March in an attempt to stop the spread of covid-19 to the country.

Trump blamed Europe for increasing US infections, as he referred to covid-19 as a horrible disease. Reading from a teleprompter, he said that while previous measures, such as travel restrictions from China, the announcement of a public health emergency, and warnings, had led to a dramatic decrease in US infections, the problem lay with Europe.

He said the US would continue to monitor the situation with China. Previously he had restricted flights from China to the US.

Trump also said that Congress had appropriated \$8.3bn (£6.5bn; $€ 7.4 \mathrm{bn})$ to help fight the pandemic, testing was becoming more available, and the risk of infection was low for healthy Americans, but was higher for the elderly. He said nursing homes should suspend visits.

The president advised people to follow guidelines for washing their hands, cleaning surfaces, covering their mouth and nose if sneezing or coughing, and staying home if they felt ill. He promised emergency assistance for workers who might lose pay if they took sick days.

Trump assured viewers that the US economy was strong. This was not a financial crisis, he said, but a temporary moment. He promised financial support to small and medium sized businesses through the Small Business Administration.

He said he would provide immediate tax relief by deferring income tax payments, ordinarily expected by 15 April, thus contributing \$200bn to the US economy.

He ended his talk by saying Americans were in this together, they would unify, and would, as always, rise to the challenge. Commenting on Trump's ban, Paul Hunter, professor in medicine at University of East Anglia, said, "It's uncertain what the US intends to achieve with the travel ban to the Schengen area of Europe. Many of us have been pointing out since the covid-19 epidemic began that travel bans have a poor record of preventing the spread of epidemic diseases. At best, travel bans only delay the spread of an epidemic by a short while. A paper published in Science showed that the travel ban in China only delayed the spread internally by 3 to 5 days. ${ }^{1}$ It also showed that international travel bans are only modestly effective at controlling international spread.

"Introducing an international travel ban at a time when the US is now one of the countries with the most rapidly accelerating internal transmission rates will do little if anything to reduce the burden of infection within the US."

1 Chinazzi M, Davis JT, Ajelli M, et al. The effect of travel restrictions on the spread of the 2019 novel coronavirus (COVID-19) outbreak. Science. 2020 Mar 6. pi:eaba9757. 10.1126/science.aba9757.

Published by the BMJ Publishing Group Limited. For permission to use (where not already granted under a licence) please go to http://group.bmj.com/group/rights-licensing/ permissions 